\title{
Effectiveness of Multidisciplinary Group-Based Intervention versus Individual Physiotherapy for Improving Chronic Low Back Pain in Nursing Staff: A Clinical Trial with 3- and 6-Month Follow-Up Visits from Tehran, Iran
}

\author{
Leila Ghadyani ${ }^{1}$, Sedigheh Sadat Tavafian ${ }^{1}$, Anoshirvan Kazemnejad ${ }^{2}$, Joan Wagner ${ }^{3}$ \\ ${ }^{1}$ Department of Health Education, Faculty of Medical Sciences, Tarbiat Modares University, Tehran, Iran \\ ${ }^{2}$ Department of Statistics, Faculty of Medical Sciences, Tarbiat Modares University, Tehran, Iran \\ ${ }^{3}$ Faculty of Nursing, University of Regina, Regina, SK, Canada
}

\begin{abstract}
Study Design: Clinical trial.
Purpose: To evaluate the effectiveness of a multidisciplinary group-based intervention on improving pain and disability among Iranian nurses with chronic low back pain in Tehran, Iran.

Overview of Literature: Although low back pain (LBP) is one of the most important health problems, the challenge remains on how to find an effective intervention to reduce pain and related disabilities.

Methods: Overall, 136 eligible nurses with chronic mechanical LBP were classified into two groups. The intervention group ( $n=66$ participants) participated in a physiotherapy educational program (for 120 minutes) plus a health educational program based on predictive constructs of the social cognitive theory (for 120 minutes). These interventions were delivered by a physiotherapist and a health education specialist. The control group ( $\mathrm{n}=70$ participants) participated in a physiotherapy educational program (for 120 minutes). Disability rate, pain severity, and back pain prevention behavior were measured initially and at 3- and 6-month follow-up visits using the visual analogue scale, Roland-Morris Disability, and Nursing Low Back Pain Preventive Behaviors Questionnaire. Data were analyzed by SPSS ver. 16 .

Results: There were statistically significant differences between the two groups in the main outcome measures immediately after the educational program and at 3-and 6-month follow-up visits. Preventive behaviors of participants in the intervention group were improved at 3- and 6 - month follow-up visits $(p<0.001)$. The mean scores of predictive constructs regarding LBP preventive behaviors in the intervention group were improved after 3 and 6 months $(p<0.001)$. Finally, in the intervention group, pain severity and disability were decreased significantly.

Conclusions: This study showed that a multidisciplinary educational program intervention can be an effective approach for reducing LBP and related disabilities among nurses.
\end{abstract}

Keywords: Chronic low back pain; Social cognitive theory; Physiotherapy; Multidisciplinary; Nursing staff

Received Jul 11, 2016; Revised Nov 2, 2016; Accepted Dec 3, 2016

Corresponding author: Sedigheh Sadat Tavafian

Department of Health Education, Faculty of Medical Sciences, Tarbiat Modares University,

Jalale Ale Ahmad, Pole Nasr, Tehran, Iran. P.O.Box: 14115-111

Tel: +98-21-82884547, Fax: +98-21-82884555, E-mail: tavafian@modares.ac.ir 


\section{Introduction}

Low back pain (LBP) is a significant health problem responsible for causing pain and disabilities worldwide while also being responsible for considerable health costs and missing work days $[1,2]$. A previous study has shown that LBP that has persisted for several months or years is often associated with psychological and social problems [1]. This suggests that chronic pain is not successfully managed by a single strategy, such as physical therapy. A previous study has shown that behaviors commonly associated with LBP, such as sick leave, fear of movement or injury, and inactivity, could be prevented/improved through planned educational interventions [3]. Workplace health promotion programs are commonly considered as strategies for lifestyle/behavior improvement that lead to improved health- and work-related outcomes and cost benefits [4].

The social cognitive theory (SCT), a health behavior change theory, provides a comprehensive and wellsupported conceptual framework for understanding the interaction of an individual's behavior and environment that influences healthcare providers' behavior [5]. Constructs of SCT include knowledge, outcome expectations, outcome expectancies, situational environment perception, self-efficiency, self-efficacy in overcoming impediments, goal setting or self-control, and emotional coping, which can all predict health behavior [5]. Because of the biopsychosocial domains of chronic pain [1], a multidisciplinary approach is expected to be an effective strategy for managing patients with chronic pain.

The authors questioned whether a multidisciplinary intervention, based on SCT, would be more effective than a monodisciplinary intervention, such as physiotherapy, which is commonly used in countries such as Iran. Nurses are very vulnerable to chronic LBP (CLBP) [6]. CLBP and related disabilities are important occupational injuries found in nurses $[7,8]$. Because it has been estimated that $62 \%$ of Iranian nurses suffer from LBP [9], we selected the nurses as subjects for this study. The purpose of this study was to compare the clinical effectiveness of multidisciplinary group-based SCT intervention to the monodisciplinary intervention of physical therapy.

\section{Materials and Methods}

The Ethics Committee of Tarbiat Modares University approved the study. The statistical sample consisted of nurses with chronic mechanical LBP working in Mostafa Khomeini Hospital, Tehran, Iran. For sampling, the hospital wards were randomly divided into two sections of intervention wards and control wards. The nurses in each section were not able to communicate with nurses in the other section. Then, the nurses with LBP from each section (intervention wards $[\mathrm{n}=136]$ and control wards $[n=140])$ were recruited. The eligible nurses who agreed to be assessed and signed the consent form were included in the study. According to this procedure, 66 nurses in intervention group and 70 participants in the control group were finally included in the study. Fig. 1 shows the methods used for sampling. The inclusion criteria were as follows: 18 years of age or older and suffering from mechanical LBP for more than 90 days. The exclusion criteria included spinal surgery within the past 2 years, congenital abnormalities in the spine, and pregnancy. Furthermore, each individual who suffered from self-reported inflammatory spondyloarthropathy or a tumor in his/her spine was excluded from the study. No physical examination or para clinical tests for diagnosing chronic mechanical LBP or other exclusion criteria were conducted.

The participants in the intervention group participated

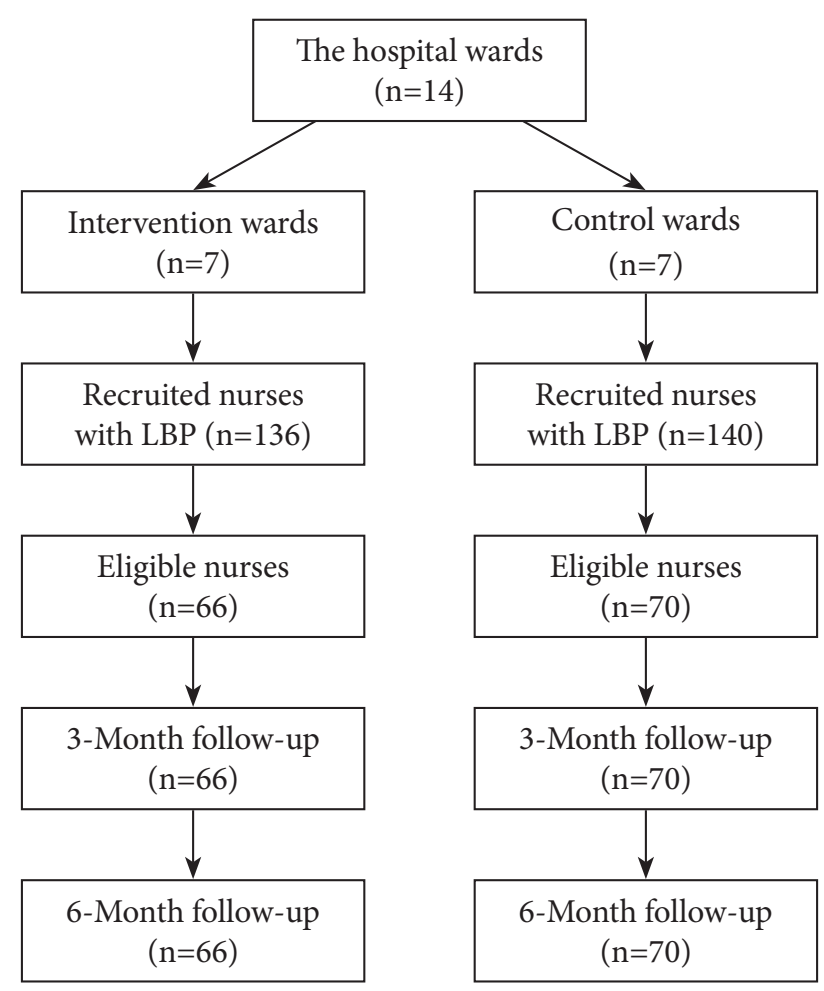

Fig. 1. Flow chart of the sampling procedure. LBP, low back pain. 
in a multidisciplinary program that was conducted by a physiotherapist and a health educational specialist. Through the educational program, the physiotherapist educated the participants on the performance of specific exercises for LBP and complying with the proper ergonomic posture of the vertebra during daily activities in a 120-minute session. The health education specialist educated and conducted the health educational program based on the predictive constructs of SCT, such as emotional coping (30 minutes), environmental perception (30 minutes), self-efficacy (30 minutes), and self-efficacy in overcoming impediments in the working environment (30 minutes). These educational sessions were conducted using group discussions, role-playing, and package training. For both groups, physical therapy was performed in a 120 -minute session. During the session, the physiotherapist educated participants of both groups on healthy postures during daily activities as well as appropriate back exercise training. The program for the intervention group lasted for 240 minutes, and the program for the control group program lasted for 120 minutes. Both groups were followed for 6 months after the intervention.

All nurses in both groups received reminders to follow the intervention. As all the nurses were eligible and working in the hospital, none were lost due to follow-up because of a lack of accessibility. Fig. 1 shows the CONSORT diagram of the participants' selection.

The data were obtained from the demographic characteristics questionnaire, the Nursing Low Back Pain Predictor Questionnaire (NLBPPQ), the preventive behavior questionnaire, the visual analogue scale (VAS), and the Roland-Morris Disability Questionnaire (RDQ). The data based on all these questionnaires was collected at baseline and 3 and 6 months after intervention.

The VAS was used to measure pain severity. This instrument is a psychometric scale for subjective characteristics that are reported by the respondent. When responding to a VAS item, respondents specify their level of agreement to a statement by indicating a position along a continuous line between two end-points of 0 as no pain and 10 as severe pain. Thus, a higher number indicates more severe pain. The validity and reliability of this instrument are reported in a previous study [10]. The RDQ measures restriction or lack of ability to perform daily activities. The RDQ includes 24 items, which are related specifically to physical function and are affected by LBP. This instrument is a health status measurement scale, designed to be completed by patients to assess physical disability due to LBP. Patients completing the RDQ were asked to place a check mark beside the statement that applied to them on a specific day. The RDQ score is calculated by summing the marked items. Thus, the score of this scale ranged from 0 (no disability) to 24 (maximum disability). A higher score indicates more disability [11]. Translation of this scale into different languages is available, and its validity/reliability is well documented [12].

In this study, the Iranian version of The RDQ was used [13]. The NLBPPQ was used to measure predictive constructs of the SCT. This instrument was developed based on the SCT and the existing literature on work-related LBP. A final 40-item questionnaire categorized into seven distinct groupings such as self-efficacy, score range (7-35); knowledge: score range (8-40); outcome perception, score range (8-40); self-control, score range (6-30); emotional coping, score range (4-20); self-efficacy in overcoming impediments, score range (4-20); and environment, score range (3-15). The internal consistency of the NLBPPQ, as assessed by the Cronbach's a coefficient, showed satisfactory results with an alpha ranging from 0.75 to 0.85 for each concept and 0.83 for the entire questionnaire. The intraclass correlation coefficient of the NLBPPQ also was found to be satisfactory, indicating that the questionnaire had good stability. In this instrument, a higher score indicated a poor condition. The development and psychometric process of this instrument as well as its validity and reliability are reported elsewhere [14]. The behavior questionnaire was on preventive behaviors, such as maintaining a healthy posture of the vertebra while performing nursing duties at the worksite and caring for patients. This questionnaire includes 13 behaviors and scored from 0 to 39. A higher score indicated a better position.

\section{Results}

A total of 136 participants were available to be contacted for a 6-month follow-up to complete the study. Table 1 shows the demographic statistics of the studied participants in both the intervention and control groups. Fortynine participants (74.2\%) in the intervention group and 50 participants $(71.4 \%)$ in the control group were female.

Table 2 shows the comparison of the predictive constructs' mean scores of both groups at the initiation of the study and at 3 and 6 months after intervention. Furthermore, Table 2 shows the trend of changes in the predictive 
Table 1. Demographic characteristics and at baseline of all participants, intervention and control group

\begin{tabular}{|c|c|c|c|}
\hline Demographic characteristic & $\begin{array}{l}\text { Control group } \\
\qquad(\mathrm{n}=70)\end{array}$ & $\begin{array}{l}\text { Intervention group } \\
\qquad(\mathrm{n}=66)\end{array}$ & $\begin{array}{c}\text { Chi-square test } \\
(p \text {-value })\end{array}$ \\
\hline Sex & & & 0.43 \\
\hline Male & $20(28.6)$ & $17(25.8)$ & \\
\hline Female & $50(71.4)$ & $49(74.2)$ & \\
\hline Age (yr) & & & 0.153 \\
\hline $18-28$ & $6(8.6)$ & $6(9.1)$ & \\
\hline $29-38$ & $35(50)$ & $22(33.1)$ & \\
\hline $39-48$ & $27(38.6)$ & $32(48.5)$ & \\
\hline$>48$ & $2(2.8)$ & $6(9.1)$ & \\
\hline Education (yr) & & & $0.09^{\mathrm{al}}$ \\
\hline Diploma (12 yr) & $24(34.3)$ & $20(30.3)$ & \\
\hline Academic associated degree (14 yr) & $20(28.6)$ & $18(27.30)$ & \\
\hline Under graduated (16 yr) & $26(37.1)$ & $28(42.2)$ & \\
\hline Marital status & & & 0.34 \\
\hline Single & $19(27.1)$ & $15(22.7)$ & \\
\hline Married & $51(72.9)$ & $51(77.3)$ & \\
\hline Work shift status & & & 0.70 \\
\hline Morning shift & $8(11.4)$ & $12(18.2)$ & \\
\hline Evening shift & $3(4.3)$ & $2(3)$ & \\
\hline Night shift & $16(22.6)$ & $13(19.7)$ & \\
\hline Rotating shift & $43(64.1)$ & 39 (59.1) & \\
\hline Employment status & & & 0.21 \\
\hline Official & $44(42.9)$ & $49(74.3)$ & \\
\hline Contractual & $26(37.2)$ & $16(25.8)$ & \\
\hline Work experience (yr) & & & 0.62 \\
\hline $1-5$ & $15(21.4)$ & $11(16.7)$ & \\
\hline $5-10$ & $16(22.9)$ & $16(24.3)$ & \\
\hline $10-15$ & $24(34.3)$ & $18(27.3)$ & \\
\hline $15-20$ & $8(11.4)$ & $13(19.7)$ & \\
\hline$>20$ & $7(10)$ & $8(12.1)$ & \\
\hline Work status (hr/wk) & & & 0.21 \\
\hline$<40$ & $14(20)$ & $10(15.2)$ & \\
\hline $40-50$ & $32(45.7)$ & $35(53)$ & \\
\hline $50-60$ & $7(10)$ & $12(18.2)$ & \\
\hline$>60$ & $17(24.3)$ & $9(13.6)$ & \\
\hline Body mass index & & & 0.46 \\
\hline$<18$ & - & $1(1.5)$ & \\
\hline $18.5-24.9$ & $31(44.3)$ & $33(50)$ & \\
\hline $25-29.9$ & $30(42.3)$ & $27(40.9)$ & \\
\hline$>30$ & $10(12.9)$ & $5(7.6)$ & \\
\hline
\end{tabular}


Table 1. Continued

\begin{tabular}{|c|c|c|c|}
\hline Demographic characteristic & $\begin{array}{l}\text { Control group } \\
\qquad(\mathrm{n}=70)\end{array}$ & $\begin{array}{l}\text { Intervention group } \\
\qquad(\mathrm{n}=66)\end{array}$ & $\begin{array}{l}\text { Chi-square test } \\
\text { (p-value) }\end{array}$ \\
\hline Duration of low back pain (yr) & & & 0.68 \\
\hline $1-5$ & $47(67.1)$ & $41(62.1)$ & \\
\hline $5-10$ & $18(25.7)$ & $20(30.30)$ & \\
\hline$>10$ & $5(7.1)$ & $5(7.6)$ & \\
\hline Low back pain with sciatica & & & 0.10 \\
\hline Yes & $26(37.1)$ & $17(25.8)$ & \\
\hline No & $44(62.9)$ & $49(74.2)$ & \\
\hline Being under treatment & & & 0.17 \\
\hline Yes & $22(31.4)$ & $15(22.7)$ & \\
\hline No & $48(68.6)$ & $51(77.3)$ & \\
\hline $\begin{array}{l}\text { Being educated regarding preventive behavior } \\
\text { before initial of the study }\end{array}$ & & & 0.20 \\
\hline Yes & $19(27.1)$ & $13(19.7)$ & \\
\hline No & 51 (72.9) & 87 (80.3) & \\
\hline
\end{tabular}

Values are presented as number (\%).

alMann-Whitney test.

Table 2. Secondary outcome measures at baseline (T0), at 3 months (T1) and at 6 months (T2) and results of repeated measure analyses variance in both studied groups

\begin{tabular}{|c|c|c|c|c|}
\hline Outcome & Initial of study & 3-Month follow-up & 6-Month follow-up & $p$-value \\
\hline Intervention group & TO $(n=66)$ & T1 (n=66) & T2 (n=66) & \\
\hline Control group & TO $(n=70)$ & $\mathrm{T1}(\mathrm{n}=70)$ & $T 2(n=70)$ & \\
\hline \multicolumn{5}{|l|}{ Secondary outcome } \\
\hline \multicolumn{5}{|l|}{ Emotional coping } \\
\hline Control $(n=70)$ & $2.30 \pm 0.70$ & $2.28 \pm 0.70$ & $2.36 \pm 0.64$ & 0.70 \\
\hline Intervention (n=66) & $3.45 \pm 0.72$ & $2.11 \pm 0.68$ & $2.03 \pm 0.63$ & $<0.001$ \\
\hline$p$-value & $<0.001$ & 0.10 & 0.002 & $<0.001^{\mathrm{a}}$ \\
\hline \multicolumn{5}{|l|}{ Environment perception } \\
\hline Control $(n=70)$ & $2.6 \pm 0.64$ & $2.6 \pm 0.66$ & $2.78 \pm 0.75$ & 0.09 \\
\hline Intervention $(\mathrm{n}=66)$ & $3.15 \pm 0.47$ & $2.09 \pm 0.55$ & $2.10 \pm 0.60$ & $<0.001$ \\
\hline$p$-value & $<0.001$ & $<0.001$ & $<0.001$ & $<0.001^{\mathrm{a}}$ \\
\hline \multicolumn{5}{|c|}{ Self-efficacy in overcoming impediment } \\
\hline Control $(n=70)$ & $2.39 \pm 0.52$ & $2.54 \pm 0.60$ & $2.56 \pm 0.68$ & 0.09 \\
\hline Intervention $(\mathrm{n}=66)$ & $2.95 \pm 0.65$ & $2.22 \pm 0.58$ & $2.22 \pm 0.67$ & $<0.001$ \\
\hline$p$-value & $<0.001$ & $<0.001$ & $<0.001$ & $<0.001^{\mathrm{a}}$ \\
\hline \multicolumn{5}{|l|}{ Self-efficiency } \\
\hline Control $(n=70)$ & $2.30 \pm 0.71$ & $2.37 \pm 0.73$ & $2.44 \pm 0.89$ & 0.25 \\
\hline Intervention (n=66) & $2.30 \pm 0.72$ & $1.95 \pm 0.62$ & $1.92 \pm 0.65$ & $<0.001$ \\
\hline$p$-value & 0.96 & $<0.001$ & $<0.001$ & $<0.001^{\mathrm{a}}$ \\
\hline
\end{tabular}

Values are presented as mean \pm SD.

a) Time and group interaction 
Table 3. Mean (SD) of primary outcome measures at baseline (TO), at 3 months (T1) and at 6 months (T2) and results of repeated measure analyses variance in both studied groups

\begin{tabular}{|c|c|c|c|c|}
\hline Variable & TO & $\mathrm{T} 1$ & $\mathrm{~T} 2$ & $p$-value \\
\hline \multicolumn{5}{|c|}{ Preventive behaviors score } \\
\hline Control $(n=70)$ & $14.17 \pm 2.25$ & $13.63 \pm 2.44$ & $13.41 \pm 2.52$ & 0.55 \\
\hline Intervention (n=66) & $14.41 \pm 2.47$ & $17.02 \pm 2.72$ & $16.85 \pm 3.21$ & $<0.001$ \\
\hline$p$-value & 0.55 & $<0.001$ & $<0.001$ & $<0.001^{\text {a) }}$ \\
\hline \multicolumn{5}{|l|}{ Pain sever (VAS score) } \\
\hline Control $(n=70)$ & $4.37 \pm 1.39$ & $4.47 \pm 1.44$ & $4.27 \pm 1.45$ & 0.67 \\
\hline Intervention $(\mathrm{n}=66)$ & $4.56 \pm 1.53$ & $4.11 \pm 1.50$ & $3.76 \pm 1.43$ & $<0.001$ \\
\hline$p$-value & 0.42 & 0.15 & 0.004 & $<0.001^{\text {a) }}$ \\
\hline \multicolumn{5}{|l|}{ Disability (RMD score) } \\
\hline Control $(n=70)$ & $6.51 \pm 2.97$ & $6.37 \pm 2.77$ & $6.49 \pm 2.67$ & 0.76 \\
\hline Intervention (n=66) & $7.08 \pm 3.45$ & $5.95 \pm 2.62$ & $5.97 \pm 2.53$ & 0.003 \\
\hline$p$-value & 0.59 & $<0.001$ & $<0.001$ & $<0.001^{\mathrm{a})}$ \\
\hline
\end{tabular}

Values are presented as mean \pm standard deviation (SD).

VAS, visual analogue scale; RMD, Roland Morris Disability.

a)Time and group interaction.

constructs' mean scores over time in each group. According to Table 2, all predictive factors related to preventative behavior in the intervention group were significantly improved after 3 months in the study $(p<0.001)$. There were no significant differences between the intervention and control groups at the 3-month follow-up in terms of emotional coping $(p=0.10)$. However, the mean difference score of the two groups regarding this predictive factor was significant $(p<0.001)$. The mean score of preventative behaviors, pain severity, and disability of the two studied groups are shown in Table 3. According to Table 3, the pain severity of the intervention group was significantly reduced from $4.11 \pm 1.50$ at baseline to $3.76 \pm 1.43$ at the 6 -month follow-up ( $p=0.03$ ). Furthermore, the disability was decreased from $0.08 \pm 3.45$ at the beginning of the study to $5.97 \pm 2.53$ at the 3 -month follow-up ( $p=0.003$ ).

The repeated ANOVA measures showed a significant difference in the intervention group for all predictive factors based on constructs of SCT (Table 2). Least significant difference tests showed significant differences between the mean scores of predictive constructs at the beginning of the study and the two follow-up visits. In spite of the similarities between the two groups at the beginning of the study, significant differences were shown between the two groups at 3-and 6-month follow-up visits in terms of predictive constructs. The interaction between the groups and time were significant for all the predictive factors
(Table 2) and the primary outcomes (Table 3).

\section{Discussion}

This clinical trial investigated the effects of multidisciplinary cognitive and behavioral therapy on pain reduction among patients 6 months after the intervention. In this study, the multidisciplinary group received education from a physiotherapist and health educational specialist; thus, more strategies were provided to the intervention group than to the control group. Previous studies have reported that a study was eligible for inclusion if the multidisciplinary rehabilitation intervention involved a physical component and one or both of a psychological component or a social/work-targeted component [15]. It could be argued that the observed significant pain reduction and behavioral change in the intervention group was related to cognitive and behavioral therapy based on SCT, which was added to an educational program conducted by the physiotherapist. The lack of an effect on pain severity in the control group may be related to the lack of behavioral change associated with the absence of predictors of SCT. As demonstrated in multidisciplinary cognitive and behavioral therapy, the general self-efficacy of the participants as well as their ability to overcome impediments in the working environment were improved after 3 months of intervention. Therefore, it might be argued that the be- 
havioral improvement in the intervention group was due to an improvement in these SCT constructs.

In the current study, self-efficacy was the most important predictor of LBP preventative behavior. Similarly, previous research showed that online psychological intervention improved self-efficacy and reduced disability in people receiving multimodal manual therapy for CLBP when compared to that in patients receiving manual therapy alone [16]. Therefore, it can be concluded that the multidisciplinary cognitive and behavioral therapy investigated in the present study could improve the selfefficacy of the intervention group and lead to a behavioral change. Self-efficacy has a significant relationship with the prediction of improved patient functioning and reduced reports of pain at the 6-month follow-up assessment [17]. In a study on the theory of self-efficacy in overcoming psychological obstacles to increase physical activity, it was revealed that self-efficacy also promotes the reduction of psychological obstacles to physical activity [18]. In the present study, LBP predictive factors, such as environment perception and emotional coping, were improved as a direct outcome of multidisciplinary cognitive and behavioral therapy based on SCT [19].

The success of this intervention program may be the result of the continued motivation of the participants to perform the recommended behavioral change aimed at reducing LBP. In addition, the participants in the intervention group were encouraged to change their workplace behavior and reduce obstacles in their work environment. However, the participants in the control group who were trained on healthy behaviors and proper exercise by physiotherapists could neither cope with the behaviors in the workplace nor overcome obstacles. A recent systematic review verified that cognitive behavioural therapy (CBT) reduced pain and disability and improved the quality of life compared to no treatment and other guideline-based active treatments for patients with LBP [20]. Additionally, the results of this study are supported by the CBT programs described in previous studies [21,22].

The important secondary outcome measures of this study were that all predictive factors (SCT constructs) for LBP preventive behavior were significantly increased at 3and 6- month follow-up visits. However, no significant effects on the primary and secondary outcomes were found for participants in the control group. This study showed that the disability of the participants had significantly improved with the multidisciplinary program compared to that with the physiotherapy educational program alone. Therefore, it is argued that multidisciplinary treatment based on SCT is much more effective than a physiotherapy educational program alone for decreasing LBP severity and disability. A lack of social support is evident in Iranian worksites. The success of the present study may be due to the social support provided to the participants during the research that impacted motivation and led to more significant results.

There are confounding factors that could be limitations of the study. In this study, there was no data regarding other treatments such as medication, physical therapy, or any other treatments participants may have undergone before participating in this study. This study was a selfreport of participant perceptions rather than an actual measurement of observable actions. Most variances at baseline were significantly different between two groups. This means that the conditions at pretreatment were different, and the intervention group who were participated in the physiotherapy educational program plus a health educational program based on predictive constructs of the SCT were significantly worse than the control group who were participated in a physiotherapy educational program at study initiation. The more significant improvements of the intervention group may be interpreted to be the result of selection bias as the intervention group included those who can be influenced more than the controls by intervention. Although this limitation can be considered for future studies, the data from follow-up visits was much better in the intervention group than in the control group, likely to be related to the multidisciplinary intervention. Although there was a statistical significant difference in pain reduction between two groups, we should consider that this improvement or difference might be not clinically meaningful. However, this is very controversial because it is unclear that such small reduction in the VAS score is clinically meaningful. This issue should be researched in future cost-effectiveness studies.

\section{Conclusions}

This study showed that multidisciplinary educational program interventions can be an effective approach for reducing LBP and related disability among nurses. However, confirmation of the results of this study is recommended through additional studies with a larger sample of nurses. 


\section{Conflict of Interest}

No potential conflict of interest relevant to this article was reported.

\section{Acknowledgments}

This work was funded by research deputy of Tarbiat Modares University. The author would like to thank them for this financial support.

\section{References}

1. Kamper SJ, Apeldoorn AT, Chiarotto A, et al. Multidisciplinary biopsychosocial rehabilitation for chronic low back pain. Cochrane Database Syst Rev 2014;(9):CD000963.

2. Goetzel RZ, D'Arco M, Thomas J, et al. Measuring the prevalence and incidence of low back pain disorders among American workers in the arospace and defense industry. J Occup Environ Med 2015;57:9981003.

3. Ree E, Lie SA, Eriksen HR, et al. Reduction in sick leave by a workplace educational low back pain intervention: a cluster randomized controlled trial. Scand J Public Health 2016;44:571-9.

4. Hendriksen IJ, Snoijer M, de Kok BP, van Vilsteren J, Hofstetter H. Effectiveness of a multilevel workplace health promotion program on vitality, health, and work-related outcomes. J Occup Environ Med 2016; 58:575-83.

5. Sharifnia SH, Haghdoust AA, Qorbani M, et al. The relationship of low back pain with psychosocial factors and psychological stress in nurses in Amol Hospitals. J Knowl Health 2010;4:27-33.

6. Daraiseh NM, Cronin SN, Davis LS, Shell RL, Karwowski W. Low back symptoms among hospital nurses, associations to individual factors and pain in multiple body regions. Int J Ind Ergon 2010;40:19-24.

7. van Hooff ML, Spruit M, O'Dowd JK, van Lankveld W, Fairbank JC, van Limbeek J. Predictive factors for successful clinical outcome 1 year after an intensive combined physical and psychological programme for chronic low back pain. Eur Spine J 2014;23:102-12.

8. Warming S, Precht DH, Suadicani P, Ebbehoj NE. Musculoskeletal complaints among nurses related to patient handling tasks and psychosocial factors-based on logbook registrations. Appl Ergon 2009;40:56976.

9. Choobineh A, Rajaeefard A, Neghab M. Association between perceived demands and musculoskeletal disorders among hospital nurses of Shiraz University of Medical Sciences: a questionnaire survey. Int J Occup Saf Ergon 2006;12:409-16.

10. Price DD, McGrath PA, Rafii A, Buckingham B. The validation of visual analogue scales as ratio scale measures for chronic and experimental pain. Pain 1983;17:45-56.

11. Roland M, Fairbank J. The Roland-Morris Disability Questionnaire and the Oswestry Disability Questionnaire. Spine (Phila Pa 1976) 2000;25:3115-24.

12. Ostelo RW, Deyo RA, Stratford P, et al. Interpreting change scores for pain and functional status in low back pain: towards international consensus regarding minimal important change. Spine (Phila Pa 1976) 2008;33:90-4.

13. Mousavi SJ, Parnianpour M, Mehdian H, Montazeri A, Mobini B. The Oswestry Disability Index, the Roland-Morris Disability Questionnaire, and the Quebec Back Pain Disability Scale: translation and validation studies of the Iranian versions. Spine (Phila Pa 1976) 2006;31:E454-9.

14. Ghadyani L, Tavafian SS, Kazemnejad A, Wagner J. Development and psychometric evaluation of Nursing Low Back Pain Predictor Questionnaire focusing on nurses suffering from chronic low back pain in Iran. Asian Spine J 2016;10:697-704.

15. Kamper SJ, Apeldoorn AT, Chiarotto A, et al. Multidisciplinary biopsychosocial rehabilitation for chronic low back pain: Cochrane systematic review and meta-analysis. BMJ 2015;350:h444.

16. Petrozzi MJ, Leaver A, Jones MK, Ferreira PH, Rubinstein SM, Mackey MG. Does an online psychological intervention improve self-efficacy and disability in people also receiving multimodal manual therapy for chronic low back pain compared to multimodal manual therapy alone? Design of a randomized controlled trial. Chiropr Man Therap 2015;23:35.

17. Altmaier EM, Russell DW, Kao CF, Lehmann TR, Weinstein JN. Role of self-efficacy in rehabilitation outcome among chronic low back pain patients. J Couns Psychol 1993;40:335-9.

18. Lee LL, Arthur A, Avis M. Using self-efficacy theory to develop interventions that help older people over- 
come psychological barriers to physical activity: a discussion paper. Int J Nurs Stud 2008;45:1690-9.

19. Glanz K, Rimer BK, Viswanath K. Health behavior and health education: theory, research, and practice. San Francisco: John Wiley \& Sons; 2008.

20. Henschke N, Ostelo RW, van Tulder MW, et al. Behavioural treatment for chronic low-back pain. Cochrane Database Syst Rev 2010;(7):CD002014.
21. Brewin CR. Understanding cognitive behaviour therapy: a retrieval competition account. Behav Res Ther 2006;44:765-84.

22. Richmond H, Hall AM, Copsey B, et al. The effectiveness of cognitive behavioural treatment for nonspecific low back pain: a systematic review and metaanalysis. PLoS One 2015;10:e0134192. 